\title{
Potencialidad de la región costera de Córdoba -Colombia- para el cultivo de tilapia nilótica
}

\author{
Potential of the Cordoba coastal region Colombia for the culture \\ of Nile tilapia
}

\author{
Misael Oviedo P, ${ }^{1 *}$ M.Sc, Samir Brú C, ${ }^{2}$ M.Sc, Víctor Atencio G, ${ }^{2}$ M.Sc, \\ Sandra Pardo $\mathrm{C}^{3}$ Ph.D.
}

\begin{abstract}
${ }^{1}$ Universidad de Córdoba, Ciencias Ambientales, SUE Caribe, Montería, Colombia. ${ }^{2}$ Universidad de Córdoba, Facultad de Medicina Veterinaria y Zootecnia. Departamento Ciencias Acuícolas. CINPIC. Montería, Colombia. ${ }^{3}$ Universidad Nacional de Colombia. Facultad Ciencias Agrarias. BIOGEM. Medellín, Colombia. *Correspondencia: m_oviedo2000@yahoo.com
\end{abstract}

Recibido: Diciembre de 2012; Aceptado: Marzo de 2013.

\section{RESUMEN}

Objetivo. Identificar las áreas con alta potencialidad para el cultivo de tilapia nilótica en la región costera de Córdoba, Colombia. Materiales y métodos. Cinco capas de información fueron incorporadas en un sistema de información geográfica: ubicación potencial de estanques, calidad del suelo, calidad del agua, infraestructura vial, población, limitantes y restricciones. Se recopiló información cartográfica, se revisaron los planes de ordenamiento territorial (POT) de los municipios costeros, se obtuvieron imágenes de satélite de la zona y se tomaron muestras de agua y suelo; esta información fue evaluada, organizada e introducida en la base de datos de sistemas de información geográfica (SIG). Se aplicaron herramientas de análisis espacial y se establecieron modelos de análisis que permitieron la generación e integración de los diferentes temas y la construcción final del mapa de aptitud para el cultivo de tilapia. Resultados. El 2\% del área de estudio resultó apta para el cultivo de tilapia nilótica. El alto índice de necesidades básicas insatisfechas (NBI) y las deficiencias en la infraestructura vial tuvieron efecto negativo sobre la potencialidad para la tilapicultura. Altas concentraciones de hierro y ligera acidez en algunas áreas posibilitan la presencia de suelos sulfatados ácidos. La alta turbidez y sólidos suspendidos afectaron la calidad del agua, además de la reducida capacidad de drenaje que en algunas áreas evidencian los riesgos de inundación. Conclusiones. El municipio de San Antero presentó la mejor aptitud para el cultivo de tilapia; sin embargo el área deltaico-estuarina, los ambientes lacustres y sus alrededores en la cuenca baja del Sinú, no resultaron aptos.

Palabras clave: Mapas, peces, sistemas de información geográfica (Fuentes: MeSH, NLM). 


\section{ABSTRACT}

Objective. To identify areas with high potential for Nile tilapia farming in the coastal region of Córdoba (Colombia). Materials and methods. Five information layers were incorporated into a geographical information system, including potential location of ponds, soil quality, water quality, road infrastructure and population, and limitations and constraints. Mapping information was collected, and land use plans (POT) of the coastal municipalities were reviewed; satellite images of the area were obtained and water and soil samples were collected. This information was evaluated, organized, and entered into the Geographical Information System (GIS) database. Spatial analysis tools were applied, and models of analysis that allowed the generation and integration of different subjects and the final construction of the suitability map for growing tilapia were established. Results. $2 \%$ of the study area was suitable for growing Nile tilapia. The high rate of unsatisfied basic needs (NBI) and deficiencies in road infrastructure had a negative effect on the potential for tilapia farming. High concentrations of iron and slight acidity in some areas suggest the presence of acid sulphate soils. High turbidity and suspended solids affected water quality, in addition to the small drainage capacity in some areas, which shows flood risk. Conclusions. The town of San Antero was the best fit for tilapia culture, but the delta-estuarine area, the lakes and surrounding environments in the lower basin of the Sinu River were not eligible.

Key words: Fish, geographic information systems, maps (Sourse: MeSH, NLM).

\section{INTRODUCCIÓN}

Las zonas costeras en Colombia históricamente han estado sometidas a una fuerte presión antrópica como consecuencia del modelo de desarrollo socio-económico, rápido crecimiento demográfico, obras de infraestructura, turismo, industria y el desarrollo de actividades agrícolas, pesqueras y acuícolas (1-3). La tendencia mundial, nacional y regional, específicamente en la zona costera del departamento de Córdoba, muestra un aumento de la actividad piscícola, en donde la tilapia sobresale como una de las especies más cultivadas $(4,5)$. En el año 2005 , la tilapia alcanzó el $49 \%$ de la producción nacional de peces de cultivo (6) y en el 2011 , de las 82.733 toneladas de la producción nacional piscícola, 48.433 toneladas fueron de tilapia, equivalentes al $58.5 \%$ del mercado nacional (5).

Las zonas costeras son vistas como ambientes apropiados para el cultivo de tilapias debido a que estos peces presentan características fisiológicas que les permiten adaptarse a los ambientes de aguas salobres y marinas, manteniendo su alta productividad. Además, la escasez y competencia por el consumo de agua dulce también han incrementado la presión para el desarrollo de la acuicultura en los ambientes costeros (7).

Cuando no es realizada una correcta planificación de la acuicultura en zonas costeras se pueden presentar impactos como destrucción y contaminación de ecosistemas, cambios en el paisaje y en los patrones hidrológicos, eutrofización, salinización, acidificación de suelos, problemas sociales y efectos negativos sobre la pesca $(8,9)$, además de alteración y reducción de hábitat para la fauna nativa (10) y aumento del cambio climático (11). La inadecuada planificación de la industria acuícola en la zona costera de Córdoba, principalmente en la región deltaico estuarina del río Sinú, ha generado problemas ambientales e incumplimiento de normas; entre la problemática identificada se tiene: alteración de los flujos y reflujos de agua, contaminación de aguas, tala de manglares y apropiación de bienes de uso público (12).

Los sistemas de información geográfica (SIG) dirigen su accionar hacia la solución de problemas territoriales, contribuyendo en el Manejo Integrado de Zonas Costeras, planificando, integrando y analizando una gran variedad de datos en un espacio geográfico conocido (13). SIGs han sido utilizados en la evaluación potencial de áreas para acuicultura (14-16), evaluar ésta potencialidad es un factor decisivo para la selección efectiva de lugares, viabilizando su sustentabilidad ambiental y económica, evitando los elevados costos que implica la producción en sitios inadecuados (17).

El objetivo del estudio fue evaluar la potencialidad de la región costera del departamento de Córdoba para el cultivo de tilapia nilótica (Oreochromis niloticus) por medio de un SIG y aplicando análisis multicriterio. 


\section{MATERIALES Y MÉTODOS}

Sitio de estudio. Se estudió la parte noroccidental del departamento de Córdoba, Colombia, entre las coordenadas $09^{\circ} 24,48^{\prime} 73^{\prime \prime}$ y $08^{\circ} 51,28^{\prime} 10^{\prime \prime}$ de latitud Norte y $75^{\circ} 42,46^{\prime} 74^{\prime \prime}$ y $76^{\circ} 25,21^{\prime} 07^{\prime \prime}$ de longitud Oeste; la cual abarca una franja de aproximadamente $21 \mathrm{~km}$ de ancho a lo largo de la línea litoral y comprende los municipios de San Antero, San Bernardo del Viento, Moñitos, Puerto Escondido, Santa Cruz de Lorica y Los Córdobas, cubriendo una extensión de aproximadamente 183.627 ha.

Recolección de la información. Se recolectaron datos relacionados con cinco temas principales o capas de información que fueron incorporadas en la base de datos del SIG: ubicación potencial de estanques, calidad del suelo, calidad del agua, la infraestructura vial y población y las limitantes y restricciones para la producción piscícola. Para esto se recopiló información cartográfica, se adquirieron dos imágenes de satélite, se estudiaron los planes de ordenamiento territorial (POT) de los seis municipios involucrados y se realizaron salidas de campo para recolectar muestras de agua y suelo.

La información cartografía se adquirió en el Instituto Geográfico Agustín Codazzi (IGAC), relacionada para el año 2002 y con escala $1: 100.000$; planchas 43BIS, 43, 50 y 51 formato DXF. Información cartográfica adicional fue extraída de los POT de cada municipio costero y de la Corporación Autónoma Regional de los Valles del Sinú y San Jorge (CVS). Dos imágenes fueron adquiridas de los satélites SPOT 4, de 20 metros, a color con cuatro bandas espectrales (imágenes SPOT 12.04.07 y la SPOT 19.04.07).

Para establecer los sitios de muestreo, primero se hizo una identificación cartográfica del terreno, identificando vías de acceso, centros poblados, afluentes y ecosistemas predominantes. Esta información y la realización de recorridos de campo facilitaron la selección de los 62 sitios de muestreos de suelo y los 74 sitios de muestreo de agua.

Se obtuvieron 186 muestras de suelo, tres por cada sitio de muestreo a 20,70 y $140 \mathrm{~cm}$ de profundidad, donde a cada una de ellas le fueron analizados los siguientes parámetros: textura, potencial de hidrógeno $(\mathrm{pH})$, materia orgánica (MO), fósforo $(\mathrm{P})$ y hierro (Fe). Para las muestras de agua se estudiaron 74 sitios, y se analizaron los siguientes parámetros: $\mathrm{pH}$, temperatura $(\mathrm{T})$, conductividad eléctrica (Cond), oxígeno disuelto (OD), saturación de oxígeno (SO), salinidad (Sal), sólidos suspendidos (SS), alcalinidad
(Alcal), nitritos (Nit), nitrógeno amoniacal (NA), turbidez (Turb) y fosfatos (Fos). Todos los sitios muestreados fueron geo-referenciados con un GPS (Garmin-GPSMAP 60CSx, Reino Unido).

Procesamiento de la información. EI procesamiento de la información recopilada buscó la generación de mapas que expresaran la distribución espacial de las variables y parámetros estudiados. Inicialmente la información cartográfica que estaba en formato análogo se pasó a formato digital, a través de los procesos de geo-referenciación y digitalización. Se utilizó el software ArcGis 9.3 del Environmental Systems Research Institute, mediante el cual se estableció una base de archivos tipo Shapefile para el área de estudio, límites municipales, cabeceras municipales, red vial, red hidrográfica, microcuencas y localización de sitios de muestreos.

Análisis espacial de la información. El análisis espacial de la información integró las variables y parámetros representados a manera de mapas en las diferentes capas de información, mediante utilización de análisis multicriterio, explicado por Xavier-Da-Silva (18). Este procedimiento permitió la integración de varias capas de información a través de sus transformaciones en unidades comparables, por medio de la asignación de pesos y calificaciones (Tabla 1).

A cada capa y a cada variable estudiada, se le asignaron pesos relativos con relación a la aptitud para el cultivo de tilapia nilótica; las capas calidad del suelo $(0.35)$ y del agua $(0.35)$ se les ponderó con mayor importancia que la ubicación potencial de estanques (0.15) y la infraestructura vial y población (0.15); para analizar la capacidad de evacuación de las aguas en las diferentes microcuencas de la zona costera se utilizó la variable densidad de drenaje (longitud de afluentes/superficie de la microcuenca), la cual se integró con los parámetros de calidad de agua, utilizando un peso equivalente al $50 \%$.

Como limitantes a la producción se identificaron amenazas ambientales y desde el punto de vista socio-económico el cubrimiento de las necesidades básicas insatisfechas (NBI) en la población. Las anteriores variables tuvieron efecto sustractivo, con pesos de 0.15 sobre las cuatro capas anteriores.

Como amenazas se identificaron áreas con riesgo de contaminación, áreas con peligro de deslizamientos y áreas con peligro de inundación. EI NBI se estableció con los resultados del Censo Nacional del 2005 y fue representado espacialmente para cada uno de los municipios 
Tabla 1. Pesos y calificaciones en el análisis de las diferentes variables estudiadas en relación con el cultivo de tilapia nilótica.

\begin{tabular}{|c|c|c|c|c|c|c|}
\hline \multicolumn{4}{|c|}{ CAPAS DE INFORMACIÓN } & \multicolumn{3}{|c|}{ RANGOS DE APTITUD } \\
\hline Peso de la capa & $\begin{array}{l}\text { Peso de la } \\
\text { variable }\end{array}$ & Variables & Unidad & No Apto 1 & $\begin{array}{c}\text { Moderadamente } \\
\text { Apto } 2\end{array}$ & Apto 3 \\
\hline \multirow[t]{2}{*}{$\begin{array}{l}\text { Ubicación potencial de estanques } \\
(0.15)\end{array}$} & 0.3 & Cobertura vegetal & - & Manglar & Pastos & $\begin{array}{c}\text { Suelos descubiertos } \\
\text { Cultivos }\end{array}$ \\
\hline & 0.7 & Pendiente del suelo & $\%$ & $>5$ & (3 a 5) & $<3$ \\
\hline \multirow[t]{5}{*}{ Calidad del suelo (0.35) } & 0.1 & $\mathrm{pH}$ & 01:01 & $<5.0$ y $>9.0$ & $\begin{array}{c}(5.0 \text { a } 5.5) \text { y }(8.5 \\
\text { a } 9.0)\end{array}$ & $(5.6$ a 8.4$)$ \\
\hline & 0.2 & Materia orgánica & $\%$ & $>3$ & $<0.5$ y $(2.6$ a 3.0$)$ & $(0.5$ a 2.5$)$ \\
\hline & 0.15 & Fósforo & $\mathrm{ppm}$ & $<5$ & $(5$ a 29) y $>60$ & $(30$ a 60$)$ \\
\hline & 0.15 & Hierro & $\mathrm{ppm}$ & $>20$ & $(17$ a 20$)$ & $<17$ \\
\hline & 0.4 & Textura & - & $\begin{array}{c}\text { Arenoso } \\
\text { Arenoso-franco } \\
\text { Arcillosos }\end{array}$ & $\begin{array}{l}\text { Franco-arenoso } \\
\text { Franco-limoso }\end{array}$ & $\begin{array}{c}\text { Franco } \\
\text { Franco-arcilloso } \\
\text { Franco-arcilloso- } \\
\text { arenoso }\end{array}$ \\
\hline \multirow[t]{13}{*}{ Calidad del agua (0.35) } & 0.06 & $\mathrm{pH}$ & 01:01 & $<5 y>9$ & $(5$ a 6.4$)$ & (6.5 a 9) \\
\hline & 0.04 & Temperatura & ${ }^{\circ} \mathrm{C}$ & $<25 y>35$ & $(31 \mathrm{a} 35)$ y $(22$ a 25$)$ & $(26$ a 30$)$ \\
\hline & 0.04 & Conductividad & $\mu \mathrm{s} / \mathrm{cm}$ & $>1500$ & $(500$ a 1500$)$ & $<500$ \\
\hline & 0.04 & Oxígeno disuelto & $\mathrm{mg} / \mathrm{L}$ & $<3 y>9$ & (3 a 5) & (5.1 a 9) \\
\hline & 0.04 & Saturación de oxígeno & $\%$ & $<50$ & $(50$ a 80$)$ & $(81$ a 100$)$ \\
\hline & 0.04 & Salinidad & ppt & $>24$ & $10-24$ & $<10$ \\
\hline & 0.04 & Alcalinidad & $\mathrm{mg} \mathrm{L}$ & $<20 y>180$ & $\begin{array}{c}(20 \text { a } 50) \text { y }(151 \text { a } \\
180)\end{array}$ & (50 a150) \\
\hline & 0.04 & Nitritos & $\mathrm{mg} / \mathrm{L}$ & $>0.2$ & $(0.1$ a 0.2$)$ & $<0.1$ \\
\hline & 0.04 & Nitrógeno amoniacal & $\mathrm{mg} / \mathrm{L}$ & $>0.2$ & 0.1 a 0.2 & $<0.1$ \\
\hline & 0.04 & Sólidos suspendidos & $\mathrm{mg} / \mathrm{L}$ & $>100$ & $50-100$ & $<50$ \\
\hline & 0.04 & Turbidez & NTU & $>40$ & $<10$ & $(10$ a 40$)$ \\
\hline & 0.04 & Fosfatos & $\mathrm{mg} / \mathrm{L}$ & $>0.4$ & $(0.2$ a 0.4$)$ y $<0.15$ & $(0.15$ a 0.19$)$ \\
\hline & 0.5 & Densidad de drenaje & $\%$ & Baja & Media & Alta \\
\hline \multirow[t]{4}{*}{ Infraestructura vial y población (0.15) } & 0.3 & Acceso a vías cercanas & $\mathrm{m}$ & $>1178$ & 1178 a 330 & $<330$ \\
\hline & 0.3 & Distancia al mercado & $\mathrm{Km}$ & $>70$ & 48 a 70 & $<48$ \\
\hline & 0.3 & Densidad vial & - & $<0.28$ & 0.28 a 0.88 & $>0.88$ \\
\hline & 0.1 & Densidad de población & - & - & - & - \\
\hline \multirow[t]{2}{*}{ Limitantes } & 0.15 & Amenazas & - & $\begin{array}{l}\text { Movimiento en masa } \\
\text { Contaminación }\end{array}$ & Inundación & Sin Amenaza \\
\hline & 0.15 & NBI & $\%$ & $>75$ & (64 a 75) & $<64$ \\
\hline
\end{tabular}

costeros. Las áreas de restricción para piscicultura se determinaron por razones legales o ambientales, por lo tanto estas áreas simplemente fueron descartadas del mapa final de aptitud.

A cada una de las variables que conformaron las diferentes capas de información se les asignaron rangos de aptitud que permitieron evaluar los diferentes resultados encontrados. Para facilitar la comparación entre las variables, se establecieron recalificaciones mediante tres rangos jerárquicos de aptitud: apto, moderadamente apto y no apto (Tabla 1).

Posteriormente utilizando los pesos, las calificaciones asignadas y las herramientas de análisis espacial del SIG, se crearon modelos matemáticos para la aptitud piscícola, en donde:

$A P=C * P$

$\mathrm{AP}=$ Aptitud piscícola

$C=$ Calificación de la aptitud para la tilapicultura.

$\mathrm{P}=$ Peso según la importancia para la tilapicultura.

Finalmente, los procedimientos algebraicos dentro del SIG permitieron generar el mapa de aptitud para el cultivo de tilapia en la zona costera del departamento de Córdoba.

\section{RESULTADOS}

La ubicación potencial de estanques (Figura 1A) muestra el predominio de amplias áreas descubiertas de vegetación natural, que pueden ser utilizadas en el establecimiento de estanques piscícolas; las áreas con pendientes mayores al $5 \%$ o con cobertura boscosa son identificadas como no aptas. El aspecto infraestructura vial y población (Figura 1B) favoreció más las áreas ubicadas al norte de la zona costera.

Muchos de los parámetros utilizados para determinar la calidad del suelo y del agua presentaron amplia variación con relación a sus medias, sus valores mínimos y máximos fueron de 1.5 a $153.7 \mathrm{ppm}$ de fósforo, de 0 a $144.2 \mathrm{ppm}$ de hierro, de 0 a 30 ppt de salinidad, de 24.7 a $1102.5 \mathrm{mg} / \mathrm{L}$ de alcalinidad, de 0 a $5.181 \mu \mathrm{s} / \mathrm{cm}$ de conductividad eléctrica, de 0 a $0.3 \mathrm{mg} / \mathrm{L}$ de nitritos, de 0 a $5.1 \mathrm{mg} / \mathrm{L}$ de nitrógeno amoniacal, de 0 a $6.1 \mathrm{mg} / \mathrm{L}$ de fosfatos, de 2.5 a 3.235 NTU de turbidez y de 0 a $3.785 \mathrm{mg} / \mathrm{L}$ de sólidos suspendidos.

Solamente, parámetros como pH en suelo $(5.0 \mathrm{a}$ 8.4), pH en agua (5.2 a 10.8), materia orgánica $(0$ a $1.61 \%)$, temperatura $\left(24.9\right.$ a $\left.33.8^{\circ} \mathrm{C}\right)$, 

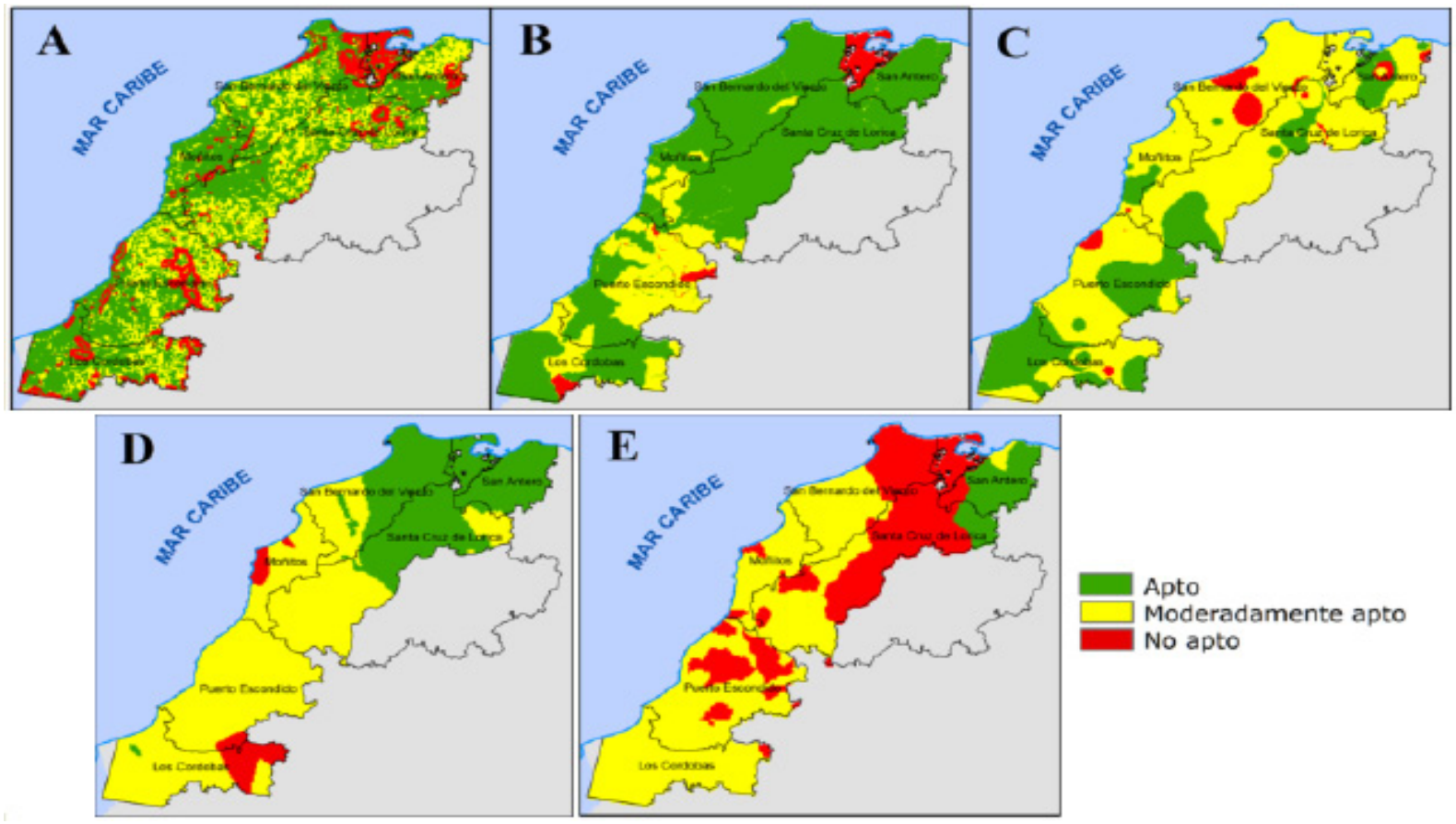

Figura 1. Representación espacial de las variables estudiadas en relación con el cultivo de tilapia nilótica. A. Ubicación potencial de estanques; B. Infraestructura vial y población; C. Calidad del suelo; D. Calidad del agua; EDensidad de drenaje.

oxígeno disuelto $(0.7$ a $8.6 \mathrm{mg} / \mathrm{L})$ y porcentaje de saturación de oxígeno (10.3 a 127.4\%) presentaron normalidad estadística.

La integración espacial de los parámetros textura, $\mathrm{pH}, \mathrm{MO}, \mathrm{P}$ y Fe, permitió la generación del mapa de calidad del suelo (Figura 1C). Los suelos de la zona costera presentaron moderada aptitud para la producción de tilapia nilótica (123.625 ha); mientras que, 6.093 ha tuvieron calificación no apta (3.3\%) y 53.909 ha fueron consideradas aptas (29.3\%). Las mayores áreas con calificación apta sobresalen hacia el sur, en los municipios de Los Córdobas, Puerto Escondido y Lorica, otras áreas aptas de menor tamaño se distinguen en Moñitos, Lorica y San Antero. Las pocas áreas no aptas en sus suelos se localizaron principalmente en la región central del municipio de San Bernardo del Viento y en el litoral de Puerto Escondido.

La integración de los doce parámetros con los que se evaluó la calidad de las aguas en los afluentes de la zona costera, generó el mapa de calidad de agua para tilapicultura (Figura 1D). La calidad del agua, con 116.478 ha también sobresalió por su moderada aptitud $(63.43 \%) ; 57.686$ ha presentaron calificación apta (31.41\%), favoreciendo los afluentes del municipio de San Antero y de las regiones central y norte de San Bernardo del Viento y Lorica. 9.463 ha fueron no aptas en sus afluentes (5.16\%), afectando la cuenca alta del río Canalete, las quebradas Morindó y Aguas Vivas, y en el municipio de Moñitos, los arroyos Ñeque, La cruz, Culebra, Pequín, Río Medio, Las Babillas y Caimito, todos estos, pequeños afluentes que vierten sus aguas directamente al mar.

Drenajes apropiados fueron identificados en el municipio de San Antero y en el noreste de Lorica, contrariamente una gran área no apta, indicando poca capacidad de drenaje y riesgo de inundación, se localizó en la región deltaico estuarina, ambientes lacustres y áreas vecinas en la cuenca baja del río Sinú (Figura 1E).

Varios eventos ambientales en la zona de estudio ofrecen amenazas para la tilapicultura, entre ellos, peligro por deslizamientos comprometiendo los municipios de Puerto Escondido y Los Córdobas, peligro de contaminación por hidrocarburos en un área pequeña al norte del municipio de San Antero, y los valles inundables de los ríos Córdoba y Sinú (Figura $2 \mathrm{~A}$ ).

Desde el punto de vista socioeconómico, la región costera de Córdoba presenta indicadores de vivienda inadecuada, servicios públicos inadecuados, hacinamiento crítico, inasistencia escolar y alta dependencia económica; situación que se traduce en un NBI con promedio superior al $75 \%$, consecuentemente ninguno de los seis municipios tuvo calificación apta (Figura 2B). 


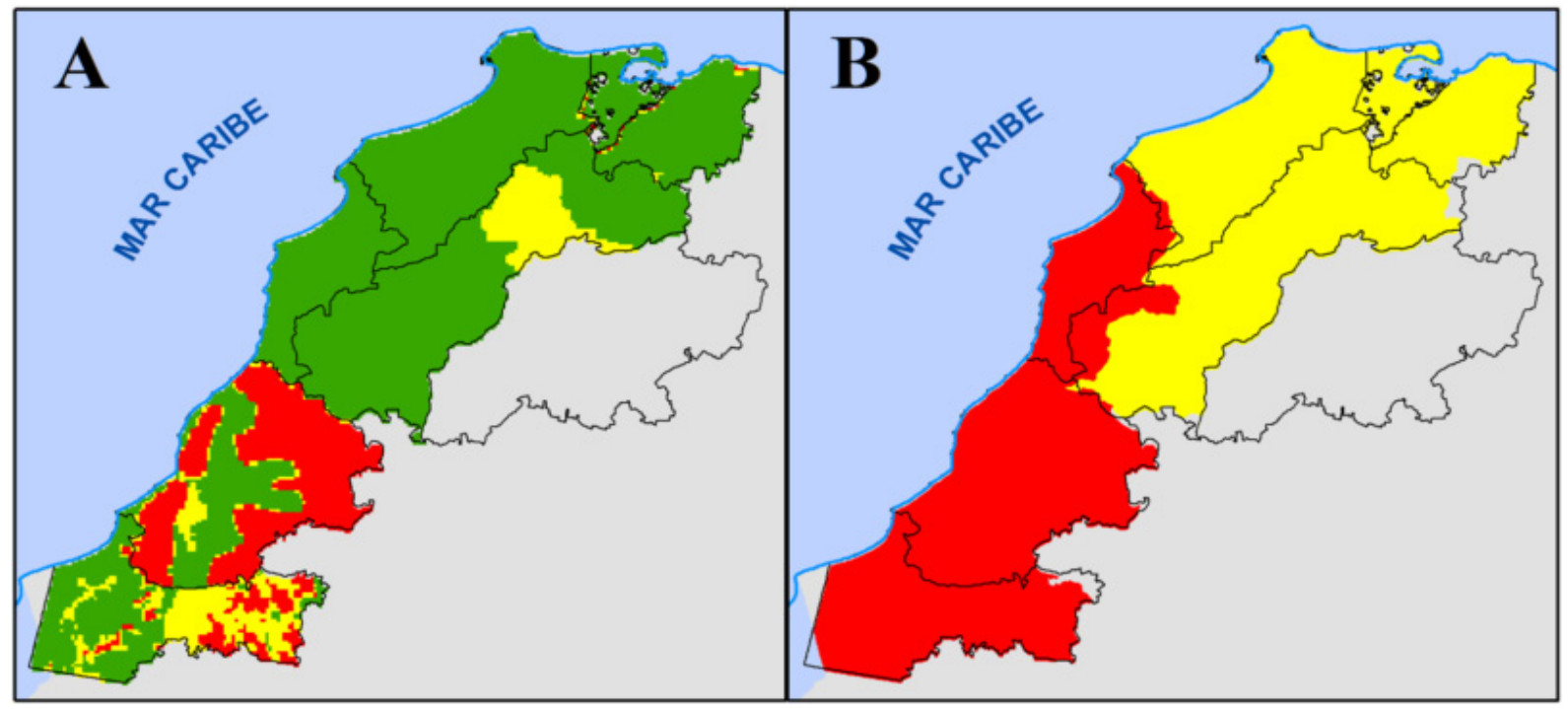

Figura 2. A. Mapa de amenazas: sin amenazas (verde), amenazas por inundación (amarillo) amenazas por deslizamiento o contaminación (rojo). B. Mapa de necesidades básicas insatisfechas: moderadamente apto (amarillo), no apto (rojo).

La integración de las diferentes capas de información generó el mapa de potencialidad de la región costera del departamento de Córdoba para el cultivo de tilapia nilótica (Figura 3), su interpretación reveló que de las 183.627 ha que conformaron el área de estudio, solamente 3.688 ha $(2.0 \%)$ son aptas para la tilapicultura, 50.684 ha $(27.6 \%)$ son moderadamente aptas y 129.255 ha $(70.4 \%)$ no son aptas. La mayor potencialidad para el establecimiento de la tilapicultura en la zona costera del departamento de Córdoba se encontró en el municipio de San Antero y noreste de Lorica.

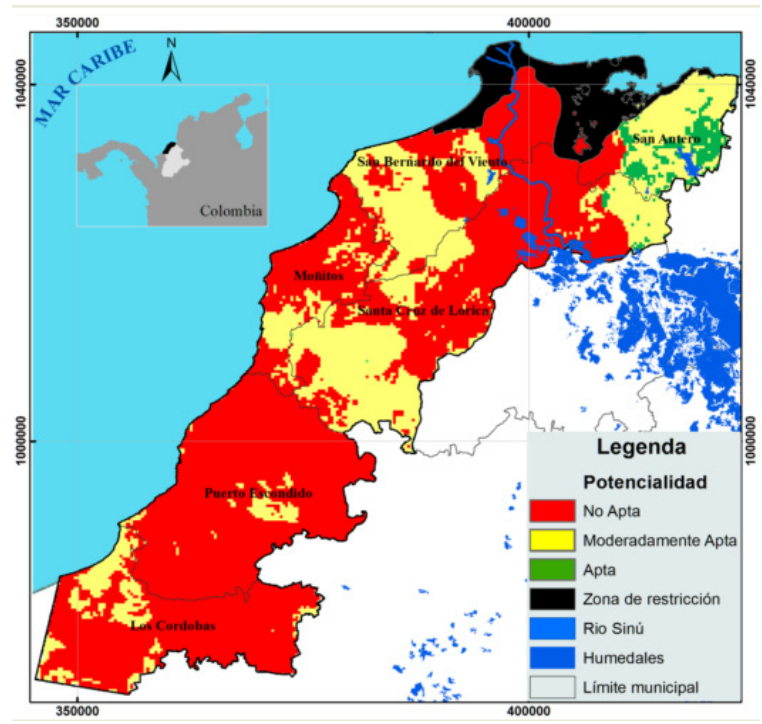

Figura 3. Mapa de potencialidad para el cultivo de tilapia nilótica en la zona costera del departamento de Córdoba.

\section{DISCUSIÓN}

Las fuertes variaciones en muchos de los parámetros utilizados para determinar la calidad del suelo y del agua en la región costera del departamento de Córdoba, son consecuencia de la diversidad de ambientes encontrados y de la inestabilidad natural de estas variables. Esta situación dificulta la caracterización generalizada de grandes áreas y la evaluación de sus potencialidades productivas, en este caso para la tilapicultura.

Aunque el mapa de calidad del suelo en general mostró adecuada aptitud para el cultivo de tilapia, las elevadas concentraciones de hierro (17.3 a 144 ppm de Fe, en 34 sitios) asociadas a la ligera acidez ( $\mathrm{pH}$ menor a 6.5, en 29 sitios) posibilitan la presentación de suelos sulfatados ácidos. De los 29 sitios con pH ligeramente ácidos, 17 tuvieron elevadas concentraciones de Fe. Las zonas costeras que contienen pirita de hierro deben ser descartadas de la presencia de suelos sulfatados ácidos antes de establecer un proyecto piscícola (19). Los suelos sulfatados ácidos de áreas inundables, con pH entre 5 a 7 , cuando son expuestos al aire se transforman en suelos extremadamente ácidos, con $\mathrm{pH}$ inferior a 4 , debido a que la pirita de hierro $\left(\mathrm{FeS}_{2}\right)$ se oxida formando sulfato de hierro II $\left(\mathrm{FeSO}_{4}\right)$, propiciando la liberación de ácido sulfúrico $\left(\mathrm{H}_{2} \mathrm{SO}_{4}\right)$ (20); estas reacciones tienen como consecuencia la muerte de los peces por lesiones branquiales (21). 
El rango óptimo de carbono orgánico para el suelo del fondo de los estanques piscícolas es de 1 a $3 \%$, correspondiendo aproximadamente el 2.0 a $6.0 \%$ de la MO presente, los suelos orgánicos deben ser evitados (19). Los niveles de MO indicaron baja concentración generalizada en la zona costera coincidiendo con estudios sobre suelos agrícolas en la región, suelos con MO entre 1.2 a $2.5 \%$ están dedicado a cultivos de papaya (22) y entre 2 a $3 \%$ a cultivos de plátano (23).

Existe una correlación positiva entre la disponibilidad de $\mathrm{P}$ y la productividad de un estanque, encontrando que en concentraciones por debajo de $13 \mathrm{mg} / \mathrm{kg}$ no hay productividad (24). Las concentraciones de P encontradas en el presente estudio indicaron moderada aptitud en la mayor parte del territorio, que puede ser corregida y mantenida con una buena gestión operativa en la granja.

Fue encontrado que 56 de los 62 sitios muestreados se caracterizaron por poseer textura franca (franco arenoso, franco arcilloso, franco limoso) considerada apta para la piscicultura. Al respecto, Boyd et al (19) consideraron que tanto los suelos arenosos como los que contienen un alto contenido de arcilla pueden ser un problema en acuicultura, dificultando los procedimientos de manejo en el estanque.

La calidad del agua presentó predominio apto hacia el norte de la zona costera y moderadamente apto hacia el centro y sur, sin embargo, es recomendado un mayor conocimiento y análisis para cada uno de los parámetros estudiados. El pH del agua en general prevaleció dentro del rango deseable para la vida de los peces (25), así como la temperatura que también se mantuvo dentro del rango apropiado para el crecimiento de la tilapia nilótica (6). Los valores de salinidad fueron muy variables, sin embargo la tilapia es capaz de tolerar un amplio rango, siendo la mejor alternativa cuando se piensa en acuicultura de agua salobre (7). La concentración de nitritos se mantuvo por debajo de la concentración letal $\left(\mathrm{CL}_{50}\right)$ de $0.63 \mathrm{mg} / \mathrm{L}$, reportada por Caballero et al (26).

Aunque los valores mínimos y máximos de oxígeno disuelto, porcentaje de saturación de oxígeno, conductividad eléctrica, fosfatos y alcalinidad fueron muy distantes, hubo en general predominio de una calificación moderadamente apta para el cultivo de tilapia, donde el empleo de tecnologías y el manejo adecuado pueden mejorar estos parámetros. Por otro lado, la rusticidad de esta especie puede soportar condiciones aún mucho más extremas, por ejemplo, la mayoría de las tilapias soportan niveles muy bajos de OD, entre 0.1 y 0.5 mg/L (27).
El amonio es muy tóxico para la tilapia, su concentración debe mantenerse por debajo de $0.1 \mathrm{mg} / \mathrm{L}$ (27). En este estudio, siete muestras presentaron valores superiores al valor tóxico, afectando la aptitud de este parámetro en grandes áreas del municipio de San Antero, Puerto Escondido y Moñitos.

Los valores de turbidez y sólidos suspendidos presentaron predominio de calificación no apta para el cultivo de tilapia. Hajek y Boyd (28) consideran que aguas con valores de turbidez inferiores a 25 NTU ofrecen limitación leve para la acuicultura, sin embargo, en el presente estudio valores mayores a 40 NTU fueron considerados no aptos; de las 74 muestras evaluadas 38 presentaron valores no aptos. Los sólidos suspendidos están directamente relacionados con el aumento de la turbidez, valores inferiores a $50 \mathrm{mg} / \mathrm{l}$ fueron considerados aptos, 31 muestras presentaron valores no aptos.

El predominio de alta turbidez y elevada concentración de sólidos suspendidos en la región costera del departamento de Córdoba puede ser reflejo por influencia de amplias áreas descubiertas de vegetación natural, que conducen a problemas de erosión y pérdida de la capacidad hídrica reguladora del suelo, coincidiendo esta apreciación con estudios realizados en la costa Caribe colombiana $(2,3)$.

Desde el punto de vista socioeconómico, la falta de vías adecuadas y los altos valores en el NBI expresaron un efecto negativo acentuado sobre la potencialidad para el cultivo de tilapia nilótica. Las zonas costeras en Colombia y principalmente sus áreas rurales son identificadas con altos indicadores de pobreza y miseria, donde durante muchos años la prestación de servicios de asistencia social ha sido descuidada (29). En este mismo sentido la distribución espacial del Indicador de Desempeño Fiscal identificó la zona costera de Córdoba con valoración vulnerable (30). Estas calificaciones sin lugar a dudas limitan el interés de los inversionistas y la capacidad productiva de la región.

La potencialidad de la zona costera del departamento de Córdoba para el cultivo de tilapia nilótica es baja, solamente 3.688 ha $(2 \%)$ tuvieron calificación apta; el área deltaico estuarina, los ambientes lacustres y sus alrededores en la cuenca baja del río Sinú, no son aptos para la tilapicultura según los criterios técnicos estudiados y según las consideraciones ambientales y legales. 
Se plantea la necesidad de nuevas investigaciones que profundicen en detalle las áreas seleccionadas. Se recomienda establecer una escala de estudio a nivel municipal a fin de conocer las particularidades en cada uno de los sitios seleccionados.

\section{Agradecimientos}

Esta investigación fue financiada por el Ministerio de Agricultura y Desarrollo Rural y el Centro de Investigación Piscícola de la Universidad de Córdoba CINPIC (Montería, Colombia), mediante el proyecto 2007U6465-430-07.

\section{REFERENCIAS}

1. Steer RR, Arias IFA, Ramos MA, Sierra CPC, Carvajal DA, Ocampo AP. Documento base para la elaboración de la Política Nacional de Ordenamiento Integrado de las Zonas Costeras Colombianas. Documento de consultoría para el Ministerio del Medio Ambiente. INVEMAR (en línea) 1997 (fecha de acceso 1 de febrero de 2013); serie publicaciones especiales (6):390 URL disponible en: http:// www.invemar.org.co/redcostera1/invemar/ docs/458ZonasCosteras.pdf

2. Restrepo JD, Zapata P, Díaz JM, Garzón-Ferreira J, García CB. Fluvial fluxes into the Caribbean Sea and their impact on coastal ecosystems: The Magdalena River, Colombia. Glob Planet Change 2006; 50:33-49.

3. Rangel-Buitrago N, Anfuso G. Assessment of coastal vulnerability in La Guajira Peninsula, Colombia Caribbean Sea. J Coast Res 2009; Special Issue 56:792-796.

4. Organización de las Naciones Unidas para la Alimentación y la Agricultura, Departamento de Pesca y Acuicultura. El estado mundial de la pesca y la acuicultura 2012. FAO (en línea) 2012. (fecha de acceso 9 de Julio de 2013); URL disponible en: http://www.fao.org/ docrep/016/i2727s/i2727s.pdf

5. Merino MC, Bonilla SP, Bages F. Diagnóstico del estado de la acuicultura en Colombia. Plan Nacional de Desarrollo de la Acuicultura Sostenible en Colombia AUNAP-FAO. Bogotá, Colombia: Ministerio de Agricultura y Desarrollo Rural; 2013.

6. Espinal GCF, Martínez Covaleda HJ, González Rodríguez FA. La cadena de la piscicultura en Colombia: una mirada global de su estructura y dinámica, 1991-2005. Ministerio de Agricultura y Desarrollo Rural, Observatorio Agrocadenas (en línea) 2005. (fecha de acceso 25 de octubre de 2012); (106):46. URL disponible en: http:// www.ibcperu.org/doc/isis/9812.pdf
7. Yan B, Wang ZH, Zhao JL. Mechanism of osmoregulatory adaptation in tilapia. Mol Biol Rep 2013; 40:925-931.

8. Azad AK, Jensen KR, Lin CK. Coastal aquaculture development in Bangladesh: unsustainable and sustainable experiences. Environ Manage 2009; 44:800-809.

9. Martinez-Porchas M, Martinez-Cordova LR. World aquaculture: environmental impacts and troubleshooting alternatives. Scientific World Journal 2012; Article ID 389623:1-9.

10. Caraballo GP. Efecto de tilapia Oreochromis niloticus sobre la producción pesquera del embalse el Guájaro Atlántico - Colombia. Rev MVZ Córdoba 2009; 14(3):1796-1802.

11. Boyd CE, Wood CW, Chaney PL, Queiroz JF. Role of aquaculture pond sediments in sequestration of annual global carbon emissions. Environ Pollut 2010; 158:2537-2540.

12. Resolución Defensoría No. 38. Estado actual de la cuenca media y baja del Sinú. Bogota, Colombia: Defensoría Del Pueblo; 2005. URL Disponible en: http://www.defensoria. org.co/red/anexos/pdf/02/res/defensorial/ defensorial38.pdf.

13. Alonso Carvajal DA, Sierra-Correa PC, AriasIsaza FA, Fontalvo Herazo ML. Conceptos y guía metodológica para el manejo integrado de zonas costeras en Colombia. Preparación, caracterización y diagnóstico. INVEMAR (en línea) 2003. (fecha de acceso 11 de julio de 2013); serie de documentos generales. URL disponible en: http://www.invemar.org.co/ redcostera1/invemar/docs/1382mizc.pdf

14. Ross LG, Mendoza EAQM, Beveridge MCM. The application of geographical information systems to site selection for coastal aquaculture: an example based on salmonid cage culture. Aquaculture 1993; 112:165-178. 
15. Buitrago J, Rada M, Hernandez H, Buitrago E. A single-use site selection technique, using GIS, for aquaculture planning: choosing locations for mangrove oyster raft culture in Margarita Island, Venezuela. Environ Manage 2005; 35(5):544-556.

16. Oviedo Pastrana ME, Puerta Avilés OA, Bru Cordero SB, Atencio García VJ, Pardo Carrasco SC. Aptitud del Suelo de la Zona Costera del Departamento de Córdoba (Colombia) para la Piscicultura. Rev Fac Nal Agr Medellín 2012; 65(1):6431-6438.

17. Meaden GJ, Kapetsky JM. Geographical information systems and remote sensing in inland fisheries and aquaculture. FAO (en línea) 1991; (fecha de acceso 3 de septiembre de 2012); Fisheries Technical Paper (318):262. URL disponible en: http://www.fao.org/ docrep/003/T0446E/T0446E00.HTM

18. Xavier Da Silva J, Tabares Zaidan R. Geoprocessamento e análise ambiental: aplicações. Rio de Janeiro, Brasil: Ed. Bertraud Brasil; 2004.

19. Boyd CE, Wood CW, Thunjai T. Aquaculture pond bottom soil quality management. Pond Dynamics / Aquaculture Collaborative Research Support Program. Corvallis, Oregon: Oregon State University; 2002.

20. Vitanea Arana L. Princípios químicos de qualidade da água em aqüicultura: uma revisão para peixes e camarões. Florianópolis, Brasil: Editorial Universidad Federal de Santa Catarina; 2004.

21. Pardo Carrasco SC, Suarez Mahecha H, Pertuz Buelvas VM. Interacción de los suelos sulfatados ácidos con el agua y sus efectos en la sobrevivencia del bocachico (Prochilodus magdalenae) en cultivo. Rev Colom Cienc Pecu 2009; 22(4):619-631.

22. Jaraba J de D, Lozano Z, Espinosa M. Nematodos agalladores asociados al cultivo de papaya (Carica papaya L.) en el departamento de Córdoba, Colombia. Agron Colomb 2007; 25(1):124-130
23. Ramos A, Durango J, Grandett G, Díaz B, Barrera JL. Evaluación de las diferentes formas de potasio en suelos de la zona platanera de Córdoba (Colombia). Agron Colomb 2006; 24(2):334-339

24. Banerjee A, Chattopadhyay GN, Boyd CE. Determination of critical limits of soil nutrients for use in optimizing fertilizer rates for fish ponds in red, lateritic soil zones. Aquac Eng 2009; 40(3): 144-148.

25. Wurts WA, Durborow RM. Interactions of $\mathrm{pH}$, carbon dioxide, alkalinity and hardness in fish ponds. Southern Regional Aquaculture Center (en line) 1992. (fecha de acceso 14 de octubre de 2012); Publication (464):4. URL disponible en: https://srac.tamu.edu/index.cfm/event/ getFactSheet/whichfactsheet/112/

26. Caballero Maury D, Calume González M, Brú Cordero S, Atencio García V, Pardo Carrasco S. Concentración letal 50 de nitrito en tilapia nilótica (Oreochromis niloticus). Rev Colom Cienc Pecu 2009; 22(3):554.

27. El-Sayed A-FM. Tilapia Culture. Oxfordshire: CABI Publishing; 2006.

28. Hajek BF, Boyd CE. Rating soil and water information for aquaculture. Aquac Eng 1994; 13(2):115-128.

29. Arias Nieto G, Suescun Mutis F, Mercer R, Bonati $\mathrm{M}$, Choonara I. Child health in Colombia. Arch Dis Child 2009; 94:900-903.

30. Departamento Nacional de Planeación. Desempeño fiscal de los departamentos y municipios 2010. Bogota D.C, Colombia: Departamento Nacional de Planeación; 2010. (fecha de acceso 9 de Julio de 2012); URL disponible en: https://www.dnp.gov.co/ LinkClick.aspx?fileticket $=8$ Y2gKqxEvgQ\%3d\& tabid $=386$ 